\title{
The Intraluminal Phase of Fat Digestion in Man: The Lipid Content of the Micellar and Oil Phases of Intestinal Content Obtained during Fat Digestion and Absorption *
}

\author{
Alan F. Hofmann † and Bengt Borgström \\ (From the Department of Physiological Chemistry, University of Lund, Lund, Sweden)
}

\begin{abstract}
For nearly a century, it has been known that dietary triglyceride is hydrolyzed in the small intestinal lumen by pancreatic lipase. Early workers had shown the presence of fatty acid (believed to be largely present as paraffin chain soap) in intestinal content after the ingestion of fat. At the turn of the century, the field of fat absorption was dominated by Pflüger, who staunchly defended the view that fat was largely hydrolyzed to fatty acid and that absorption could only be in the form of fatty acid and paraffin chain soap (3). The observation that paraffin chain soap was insoluble at the rather acid $\mathrm{pH}$ of intestinal content was disturbing, but seemed of little importance after Verzár and McDougall demonstrated the considerable solubility of fatty acids in bile salt solutions at a $\mathrm{pH}$ corresponding to that present in intestinal content (4). In 1935, however, Artom and Reale (5) demonstrated that monoglycerides and diglycerides could be isolated after triglyceride was hydrolyzed by pancreatic lipase in vitro. Their presence in intestinal content was established by Frazer and Sammons in 1945 (6).
\end{abstract}

Frazer, Schulman, and Stewart (7) subsequently noted that triolein forms a stable emulsion in an aqueous mixture of bile salt, fatty acid,

* Submitted for publication July 30, 1963; accepted October 17, 1963.

This study was supported by the National Foundation (U. S. A.), the National Heart Institute, grant H-5302, Metabolism (U. S. Public Health Service), and the Swedish Medical Research Council.

Portions of this work have been presented at the Forty-fifth Annual Meeting of the Federation of American Societies for Experimental Biology (1) and the Fifty-fifth Annual Meeting of the American Society for Clinical Investigation (2).

$\dagger$ Present address: The Rockefeller Institute, New York 21, N. Y. and monoglyceride. Frazer (8) has since presented numerous experiments supporting the view that lipid is absorbed, at least in part, as a triglyceride emulsion. However, the delineation of the fine anatomical structure of the brush border of the intestinal epithelial cell by the electron microscope $(9,10)$ and progress in the understanding of pancreatic lipolysis (1) have necessitated a reconsideration of the physicochemical form in which lipid passes into the mucosal cell from the intestinal lumen.

In 1897, in an elegant and seldom cited paper, Moore and Rockwood (11) reported that active fat absorption could be observed from a loop of intestine whose contents did not appear to be emulsion. These workers also demonstrated that bile salt solutions could dissolve large amounts of fatty acids, and they were quite puzzled by this phenomenon. It is now recognized that the ability of bile salt solutions to dissolve lipids is merely a reflection of their detergent properties (12-14). Above a critical concentration, bile salt molecules aggregate to form micelles; such micellar aggregation is a characteristic of all detergents (15-17). All micellar solutions dissolve water insoluble materials to some extent, as the inside of the micelle can be considered as a separate, nonaqueous phase with distinctive solvent properties (18).

Fatty acids and monoglycerides possess a remarkable solubility in bile salt solutions $(14,19)$. We have recently presented preliminary evidence for these lipids being present in micellar solution during fat digestion and absorption $(1,2)$. We now describe experiments in detail in which we have collected human intestinal content during fat digestion and absorption and have separated it by ultracentrifugation at $37^{\circ} \mathrm{C}$ into an infranatant micellar phase and a supernatant oil phase. 
The lipids of each of these phases have been quantified. The results support the conception that a micellar phase containing bile salt, fatty acid, and monoglyceride is present during fat digestion and absorption and that lipid is absorbed from such a micellar solution.

\section{Methods}

Healthy male or female medical students, 19 to 30 years, were intubated with polyvinyl tubing, as described by Blankenhorn, Hirsch, and Ahrens (20), on the evening preceding the experiment. They were directed to take only water by mouth. The following morning, when the tubing had passed at least as far as the duodenum, they were fed a test meal containing lipid in the form of corn oil. The composition of the formula meal, which contained about $550 \mathrm{kcal}$ and weighed 400 $\mathrm{g}$, has been described by Dahlqvist and Borgström (21). On one occasion, a subject ate a meal of broiled chicken, rice, custard, and milk, instead of the test meal.

Intestinal content was collected by siphonage. It was heated instantaneously to $70^{\circ} \mathrm{C}$ and kept at $70^{\circ} \mathrm{C}$ for 10 minutes to inactivate pancreatic lipase. A battery of small Erlenmeyer flasks was used. Contents were collected for an interval of 1 minute while the flask was swirled rapidly by hand in a $70^{\circ} \mathrm{C}$ water bath; the flask was then incubated in the water bath for an additional 9 minutes. The tip of the tubing was placed into a new flask each minute. After a flask had been kept at $70^{\circ} \mathrm{C}$ for 10 minutes, it was poured into a large flask kept at room temperature. Samples were generally pooled at each half hour, each pooled collection containing 301 -minute collections. The collection of intestinal content from the subject was continued until the flow became negligible or the lipid content of the fluid was negligible as judged by thin-layer chromatography (22). This was 2 to 3 hours after the feeding of the meal.

The pooled half-hour collections were taken to a $37^{\circ}$ $\mathrm{C}$ constant temperature room, where a Spinco ultracentrifuge rotor and tubes had been equilibrated at $37^{\circ} \mathrm{C}$. The samples were centrifuged overnight (usually 18 hours) in a Spinco model $\mathrm{L}$ preparative ultracentrifuge at $100,000 \times g$. The refrigeration of the rotor housing was not used during the run, and the rotor and contents remained at 36 to $40^{\circ} \mathrm{C}$ during the run, as judged from the temperature of a tube of water spun at the same time.

The tubes were removed from the rotor without agitation. A transparent nonopalescent, brown-yellow or green-brown solution was present in the upper half of the tube in nearly all of the samples. Below this, the solution became turbid from suspended particles. On the bottom was a thick pellet. Oil droplets were present at the surface in most samples. In occasional samples collected during early digestion, the oil phase was much greater in volume and was present as a separate, oily layer, composing up to $5 \%$ by volume.
A needle was inserted through the wall of the tube, and a sample of the transparent, micellar solution, termed micellar phase, was aspirated with a syringe and transferred to a graduated, glass-stoppered tube. When possible, the tube closure was then removed carefully, and 5 or $10 \mu \mathrm{l}$ was aspirated from the oil droplets present on the surface. This sample was termed the oil phase.

Generally, samples were run in duplicate or triplicate. A second tube of the same collection was shaken vigorously and then 4 to $5 \mathrm{ml}$ was aspirated with a needle as described. The lipid of these samples was termed total as it contained both micellar phase lipid and oil phase lipid, the oil phase being emulsified throughout the solution during the vigorous shaking procedure. The large volumes of intestinal content collected made possible duplicate analyses of both micellar and total phases.

The volumes of the samples of the micellar and total phases were recorded, and the lipid was extracted using a liquid to liquid extraction system developed by Blankenhorn and Ahrens (23) consisting of water: diethyl ether: heptane: ethanol (1:1:1:1, by volume). To 1 vol of intestinal content was added 3 vol of diethyl ether: heptane: ethanol $(1: 1: 1$, by volume). The upper phase, essentially diethyl ether:heptane, was aspirated with a pipette, and the lower phase was extracted two additional times with pre-equilibrated upper phase. Such an extraction procedure removes all the giycerides and fatty acids, some of the phospholipids, and none of the conjugated bile salts (24), including glycochenodeoxycholic acid, if the lower phase is not acidified, and the extraction procedure is carried out promptly.

The oil phase was pipetted directly into chloroform: methanol ( $2: 1$, by volume).

The pooled extracts of the miceliar and total phases, as well as the chloroform phases of the oil methanol solutions, were blown to dryness with a nitrogen stream and dissolved in petroleum ether. After drying with sodium sulfate, the petroleum ether solution was filtered and evaporated using a water-line vacuum. The residue was dried in a desiccator for 24 hours. The lipids were determined gravimetrically to give total lipid in milligrams per milliliter of intestinal content. The weighed sample was dissolved in petroleum ether to a known volume. A sample was blown down under a nitrogen stream, dissolved in absolute ethanol, and titrated with $0.02 \mathrm{~N}$ methanolic $\mathrm{KOH}$, with bromthymol blue as indicator. Another sample was applied to a silicic acid column. ${ }^{1}$ Triglycerides were eluted with $5 \%$ ethyl ether in heptane; diglycerides with $20 \%$ ethyl ether in heptane; and monoglycerides with ethyl ether. The fractions were examined qualitatively for purity by thinlayer chromatography. Ester bond determinations were performed by the ferric chloride and hydroxymate method of Rapport and Alonzo (25). Standard curves were run with each determination.

1- and 2-monoglyceride analyses were performed on other samples of intestinal content by periodate oxidation (26) before and after perchloric acid-induced

\footnotetext{
1 Unisil, Clarkson Chemical Co., Williamsport, Pa.
} 
isomerization (27). Heat inactivation was not performed, and extraction was carried out as described within 3 minutes of collection. The pooled diethyl ether and heptane phases were evaporated with vacuum from round-bottomed flasks without warming, and the residue was stored in a desiccator at $+5^{\circ} \mathrm{C}$ for not more than 24 hours before analysis. Control experiments with 2-monopalmitin and 2-monoolein had shown that such an extraction procedure caused no detectable isomerization.

Thin-layer chromatography was performed on microscope slides (28) or $20-\times 20$-cm p'ates using diethyl ether and petroleum ether combinations as solvent systems on plates of Silica Gel G. ${ }^{2}$ Examination of fresh intestinal content for 2-monoglyceride content was carried out using hydroxyapatite as adsorbent (29). Extraction procedures were tested by solvent systems previously developed for bile acids (30) and phospholipids (28).

Preliminary experiments had shown that if fresh intestinal content is kept either at room temperature or at $5^{\circ} \mathrm{C}$, lipolysis continues. Pancreatic lipase activity was measured on a triolein substrate as described by Borgström (31); heating intestinal content to $60^{\circ} \mathrm{C}$ for 10 minutes completely abolished lipase activity in agreement with the older observations of Terroine (32). Therefore, the heat inactivation procedure (10 minutes at $70^{\circ} \mathrm{C}$ ) was employed as described.

Control experiments showed that such heat inactivation or subsequent maintenance at $70^{\circ} \mathrm{C}$ for 1 hour did not alter the glyceride or fatty acid composition of intestinal content. A heat inactivated sample kept at $37^{\circ} \mathrm{C}$ for 40 hours showed a $10 \%$ loss in monoglyceride content, but no significant change in diglyceride or triglyceride content. Another sample of intestinal content was divided into three portions: the first was extracted immediately; the second was heated to $70^{\circ} \mathrm{C}$ rapidly and held at that temperature for 10 minutes; and the third, after heat inactivation, was kept at $37^{\circ} \mathrm{C}$ for 15 hours before extraction. Thin-layer chromatography of the three samples showed no apparent difference in fatty acid or glyceride composition. The bile acids of all three samples were entirely present as conjugates. Although it is possible that lipolysis continued at a slow rate during the lengthy ultracentrifugation procedure, such a minor degree of lipolysis should have little influence on the analytical results, as all samples of a given collection were treated identically.

The results are expressed as milligrams of monoglyceride, diglyceride, triglyceride, and fatty acid per milliliter of intestinal content. In Table I, molar percentages are shown, but in the figures, percentages by weight are used for convenience. As phospholipid and cholesterol analyses were not performed, the percentages by weight do not take into account all of the lipid species present in intestinal content; however, the majority of lipid present after the feeding of such a formula meal is fatty acid and glyceride $(22,33)$. The sum of the

2 E. Merck, A. G., Darmstadt, Germany. determined values for glyceride and fatty acid was 70 to $110 \%$ of the total lipid determined gravimetrically, the difference representing phospholipid, free and esterified cholesterol, and analytical error. In some of the samples, the sum of the values for glyceride and fatty acid was greater than $100 \%$. The reason for this apparent analytical error is unknown, but appears to be due to incorrect titration values.

Only two samples of the oil phase were analyzed completely, although others were examined chromatographically. Since the lipid of the total phase is the sum of micellar and oil phase lipid, it was possible to calculate the approximate composition of the oil phase by subtraction, in those samples in which both total and micellar phases were analyzed.

\section{Results}

The time and site of the collections with complete analyses are shown in Table I. The concentration of micellar lipid ranges from 2 to $7 \mathrm{mg}$ per $\mathrm{ml}$. As the oil phase contained little or no water, its lipid concentration should be about 920 $\mathrm{mg}$ per $\mathrm{ml}$ (the specific gravities of fatty acid, mono-, di-, and triglycerides are between 0.91 and 0.94 ). The lipid concentration of the samples termed "total," in which the lipid comprises both that of the oil and micellar phases, ranged from 12 to $35 \mathrm{mg}$ per $\mathrm{ml}$. The oil phase was a very small fraction of intestinal content when considered with respect to volume in these collections. The majority of lipid present was fatty acid, especially when the molar composition of the samples is considered.

The samples collected during different intervals showed no systematic differences in composition in accordance with the view that the ingested meal is stored in the stomach and released continually in small portions that undergo digestion independently as they pass down the intestinal tract (34). The analytical values in Table I were obtained on samples collected over time periods of at least 30 minutes. Therefore, the aspirated intestinal content represented samples of a number of portions of the meal, which might vary widely in the extent to which digestion has progressed. Occasionally, samples of intestinal content were collected that were quite clear and contained little lipid (usually 1 to $2 \mathrm{mg}$ per $\mathrm{ml}$ ). The lipid of such samples was almost exclusively fatty acid and cholesterol, as determined by thinlayer chromatography of a lipid extract. An oil phase was not present. Such samples apparently 
represented a bolus of intestinal content that had been completely digested and from which extensive absorption had already taken place.

In Figure 1, the analyses in percentage composition by weight of the micellar and oil phases are plotted, without respect to time or location of collection. The oil-phase values obtained by subtraction of the micellar lipid figures from the total lipid figures are indicated. In percentage composition by weight, the micellar phases were composed chiefly of fatty acid and monoglyceride, with much lower concentrations of diglyceride and triglyceride. The oil-phase values were richer in diglyceride and triglyceride and lower in fatty acid. These differences are statistically significant $(\mathrm{p}<0.001)(35)$; however, that of the monoglyceride percentage composition is not.

In Figure 2, the percentage composition by weight for the micellar and oil phases of five individual collections has been graphed. The data

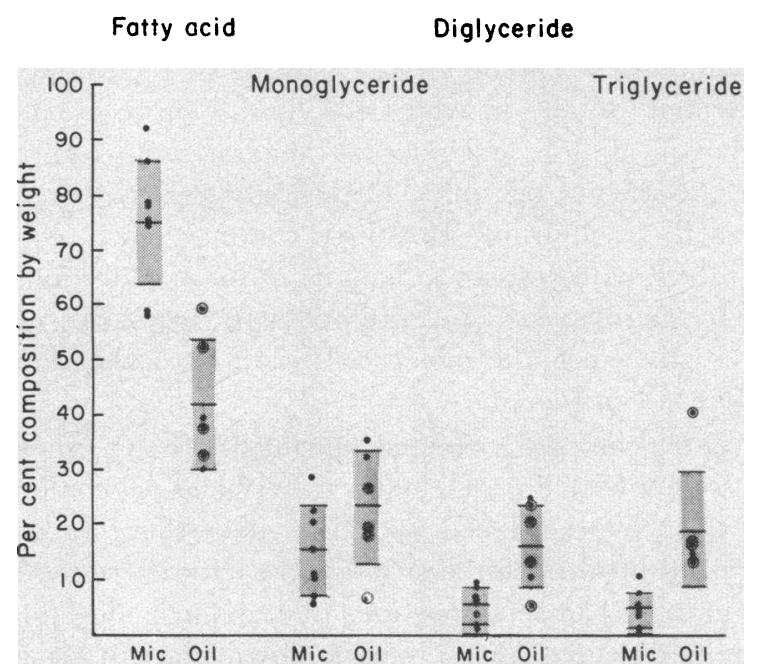

Fig. 1. THE COMPOSITION OF FATTY ACID, MONOGLYCERIDE, DIGLYCERIDE, AND TRIGLYCERIDE AS PERCENTAGE BY WEIGHT OF THE SUM OF DETERMINED FATTY ACID, MONOGLYCERIDE, DIGLYCERIDE, AND TRIGLYCERIDE FOR THE MICEllar (Mic.) AND oIl PHASES. The figures are from all samples and are plotted without respect to time or site of collection. When analyses were performed in duplicate (see Table I), the average of the two values is plotted. Values for the oil phase were determined by analysis of the isolated oil phase $(\bullet)$ or by subtraction of the micellar lipid values from the total lipid values ( ). The mean and standard deviation of each set of figures are shown. The means for fatty acid, diglyceride, and triglyceride values of the oil and micellar phases are significantly different $(p<0.001)$. from collections 22 and 23 represent analyses that were done on the isolated micellar and oil phases. In the remaining four, the micellar and total phases were analyzed, and the composition of the oil phase obtained by difference. As in Figure 1, the micellar phase is composed chiefly of fatty acid and monoglyceride. The fatty acid fraction of the oil phase is smaller, and the diglyceride and triglyceride fractions are larger. The lipid content of each phase in percentage of the total lipid present is shown. The three samples on the right were all quite rich in lipid, and in these samples, the majority of lipid present was in the oil phase. Therefore, most of the diglycerides and triglycerides of these samples were in the oil phase.

Type of diglyceride isomer present. There is considerable evidence for the near absolute specificity of pancreatic lipase for the 1-ester position in triglycerides (36). Therefore, all diglycerides present in intestinal content should be the less stable 1,2 isomer, if no isomerism occurs. The 1,2 and 1,3 diglyceride isomers are easily separated by thin-layer chromatography $(1,37)$, and two-dimensional chromatography indicates that no isomerization occurs during the chromatographic procedure (28). Thin-layer chromatography of the lipids of freshly extracted intestinal content showed only the 1,2 isomer present in a number of samples.

Type of monoglyceride isomer present. Similarly, the monoglyceride present in intestinal content should all be in the form of the less stable 2 -isomer, if the positional specificity of pancreatic lipase is absolute and no isomerization of monoglyceride (or diglyceride) occurs. Analyses of samples by extraction procedures that produced no isomerization of reference compounds showed that the majority of monoglycerides present was the 2-isomer. Five analyses were performed, and the percentage of monoglyceride present as the 2 -isomer was $76,66,67,53$, and $72 \%$. As the percentage of the 2 -isomer is calculated as total periodate-oxidizable material after perchloric acidinduced isomerization minus periodate oxidizable material before perchloric acid-induced isomerization, any periodate oxidizable material in the lipid extract that is not 1 -monoglyceride will give an erroneously high 1-monoglyceride percentage and a corresponding erroneously low 2-monoglyceride percentage. 


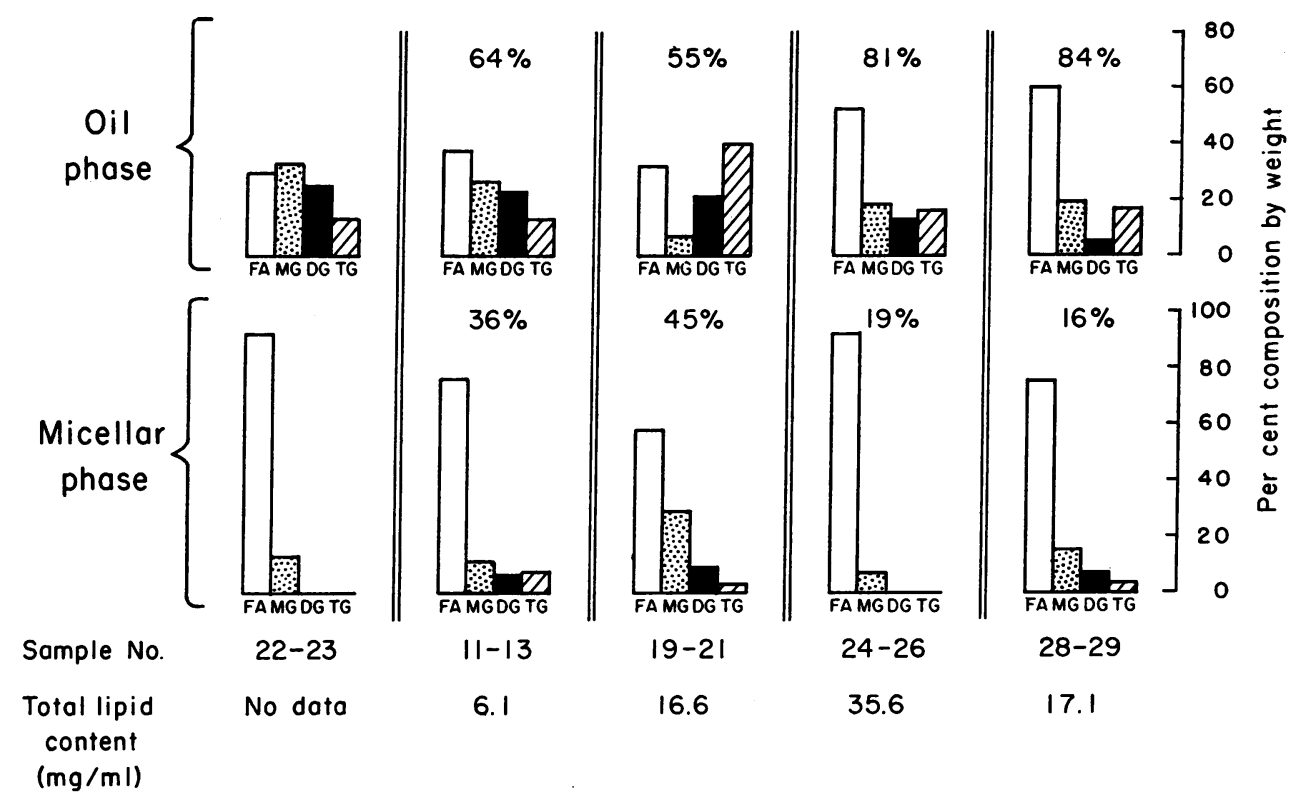

Fig. 2. The composition of the micellar and oll phases as percentage by Weight of THE SUM OF DETERMINED FATTY ACID (FA), MONOGLYCERIDE (MG), DIGLYCERIDE (DG), AND TRIGLYCERIDE (TG). The oil phase of samples 22-23 was analyzed; the values for the oil phases of the remaining samples were calculated by subtracting the micellar lipid from the total lipid. The total lipid content of the samples is shown. The figures above the bars indicate the percentage of the total lipid in the oil or micellar phase.

\section{Discussion}

The data indicate clearly that after prolonged ultracentrifugation the lipids of intestinal content occur in two separate phases and that these phases differ significantly in their lipid composition. Whether the separation of intestinal content into these two phases is an artifact resulting from the isolation procedure must be considered.

Preliminary experiments showed that an essentially clear infranatant oil phase could be obtained with much briefer periods of centrifugation, e.g., 2 hours. Borgström (33) has also shown that the lipid composition of a clear infranatant oil phase obtained on centrifuging human intestinal content was identical if the sample was spun at $10,000 \times g$ for 20 minutes or $144,000 \times g$ for 45 minutes; his experiments differed from these in that the centrifugation was performed at $0^{\circ} \mathrm{C}$. Dowse, Saunders, and Schofield (38) had previously reported that intestinal content could be separated by centrifugation at $1,000 \times g$ for 15 minutes into an upper oily layer and a "lower watery layer containing highly emulsified lipid." An overnight centrifugation period was used in these experiments as we sought to obtain a water-clear infranatant phase to be certain that a solution could be obtained that did not scatter visible light.

Studies on model systems have demonstrated that the critical micellar concentration of bile salt solutions is well below the observed concentration of bile salt in intestinal content during fat digestion and absorption (14) and that fatty acid and monoglyceride dissolve readily in micellar bile salt solution under experimental conditions simulating those present in the small intestinal lumen. When the concentration of fatty acid or monoglyceride in such a model system exceeds its respective micellar solubility in a bile salt solution, the excess appears to be emulsified. This turbid system is actually a dispersion of liquid crystalline aggregates containing bile salt and water and the excess fatty acid or monoglyceride (14). Therefore, if only bile salt fatty acid and monoglyceride were present in intestinal content, a micellar solution should occur, if there were no other molecular species to make the system behave differently 
than in the model system and the concentration of fatty acid and monoglyceride was less than their micellar solubility. If the concentration of fatty acid and monoglyceride was above that which could be solubilized into isotropic micellar solution, then intestinal content should contain a micellar solution in equilibrium with a dispersion of liquid crystalline aggregates.

In other studies in the model system, the solubility of diglyceride and triglyceride in bile salt solution was found, by contrast, to be extremely low (1). An excess separated as an emulsion, but the emulsion contained undissolved diglyceride or triglyceride and did not contain bile salt or water (1). If moderate concentrations of diglyceride and triglyceride were present in intestinal content, these lipids should exist in the form of typical emulsion droplets. The size of the emulsion particle and the stability of such an emulsion would be influenced by many factors, especially the concentration and type of emulsifier present and the nature of the layer present at the oil-water interface.

Therefore, two possibilities seem most worthy of consideration. Either all of the lipids present in intestinal content are present as emulsified droplets and the liquid phase between the droplets is ionic and nonmicellar, or an emulsified oil phase coexists with a micellar phase.

If all of the intestinal lipids and the bile salts were present as a stable emulsion, then a brief centrifugation would remove all the lipids including the bile salts from the infranatant phase. It can easily be demonstrated that this does not occur.

All of the lipid and the bile salt of intestinal content might be present in a very unstable emulsion. In this case, a brief centrifugation should result in the coalescence of the droplets with the formation of an oil phase above, and bile salts and possibly other emulsifying lipids in the infranatant phase. Indeed, such results were obtained in the experiments reported here.

In general, however, when an oil is emulsified in a detergent solution well above its critical micellar concentration, only a fraction of the detergent anions present accumulates at the oil and water interface, if the volume of the oil phase (and accordingly the interface) is relatively small (39). The negligible volume of the oil phase in intestinal content has already been noted. Moreover, inspection of intestinal content by ordinary illumination as well as dark field microscopy indicates that emulsification is quite incomplete (38). It would seem therefore that the interfacial area should be small relative to the concentration of surface active materials present in intestinal content-lecithin, lysolecithin $(40,41)$, bile salts, unionized fatty acid, fatty acid anions, monoglycerides, and proteins, among others. It seems likely that the fraction of bile salt anions present at the oil and water interface is small and that the concentration of bile salt anions in solution will be well above the critical micellar concentration of the system. Bile salts would therefore be in micellar aggregration despite the coexistence of an emulsified lipid phase.

The presence of fatty acid and monoglyceride in the micellar phase is evidence for the great affinity of the bile salt micelle for these polar lipids. The bile salt micelle has distinctive solvent properties toward such compounds $(14,42)$. The fatty acids and monoglycerides can be considered conceptually to be partitioned between a micellar and an oil phase $(18,43)$. It is possible to measure the partition coefficient of monoolein between triolein and micellar bile salt solution. For a solution of sodium taurodeoxycholate at 4 $\mathrm{mM}$, the partition coefficient of 1-monoolein is about 30 expressed as (monoolein concentration per milliliter triglyceride)/(monoolein concentration per milliliter bile salt solution) (42). Since the monoolein is insoluble in water, it is more correct to calculate the partition coefficient between triolein and the micellar fraction of the bile salt solution, the interior of the micelle being considered as a pseudophase. The micellar fraction cannot be expressed in volume units, but a partition coefficient may be defined as ( $\mu$ mole monoglyceride $/ \mu$ mole triolein $) /(\mu$ mole monoglyceride/ $\mu$ mole micellar bile salt). The much lower value of 0.1 is obtained, consistent with the high affinity of bile salt solution for monoglyceride.

The concentration of diglyceride and triglyceride in the micellar phase is higher in most samples than would have been predicted from the very low solubility of diglyceride and triglyceride in bile salt solution. Monoglyceride solubilization enhances diglyceride solubilization (42), however, and might also enhance triglyceride solubilization. 
Moreover, the bile salt micelle in intestinal content, in addition to fatty acid and monoglyceride, also contains cholesterol and lysolecithin. There is no information available on the solubility of diglyceride and triglyceride in such a complex, mixed micelle.

The data of the analyses of the "total" phase are in satisfactory agreement with others reported for human intestinal content by Blankenhorn and Ahrens (23), Ahrens and Borgström (44), and Borgström, Tryding, and Westöö (45) considering the sampling problem. Interpretation of such data is hazardous, for the system is an open one with a constant addition and removal of a lipid mixture of unknown composition. Nevertheless, some conclusions seem possible.

It is generally held that the dominant chemical sequence of intraluminal lipolysis is: triglyceride $\rightarrow 1,2$ diglyceride + fatty acid $\rightarrow 2$-monoglyceride + fatty acid. If it is assumed that no monoglyceride whatsoever is hydrolyzed, then for each monoglyceride molecule, there must be two fatty acid molecules and for each diglyceride molecule, one molecule of fatty acid. Therefore, in molar percentages: $\%$ diglyceride +2 ( $\%$ monoglyceride $)=\%$ fatty acid. It has been established that each of the steps in the above scheme of lipolysis is reversible $(44,46)$. Therefore, in a closed system where lipid was neither added nor removed, the concentration of each of these four lipid species would be determined by the net rate constants of these reversible equations. However, irrespective of the concentration of any of the partial glycerides, the equation indicated must always hold. The system can be altered to an open system more closely resembling the physiological state by postulating the removal, i.e., absorption, of fatty acids, partial glycerides, or both. The continuous addition of triglyceride to the system will not influence the equation.

If the recent analytical values published for human intestinal content $(23,44,45)$, and those of Knoebel and Ryan (47) obtained on canine intestinal content, are calculated in molar percentages, a molar excess of fatty acid is found in each case with a mean of $38 \%$ (range, 5 to $57 \%$ ). This molar excess of fatty acid which we observed also (Table I) means that 1 ) there is an additional source of fatty acid, other than from triglyceride or diglyceride, or 2) the rate of ab- sorption of diglyceride, monoglyceride, or fatty acid makes the equation unbalanced, its left side being smaller than the right, or 3 ) both possibilities may be true. There is experimental evidence for both.

It is well established that some complete hydrolysis of ingested triglyceride occurs, resulting in the liberation of three fatty acids and glycerol (48). This step is irreversible in that glycerol from ingested triglyceride is not reacylated in the lumen $(49,50)$. Incubation of triglyceride with high concentrations of pancreatic lipase in vitro results in complete digestion of triglyceride to fatty acid and glycerol $(51,52)$. Our analyses suggest that some 1-monoglyceride may be present in intestinal content, and it is well established that ingested 1-monoglyceride is hydrolyzed in vivo in man (53) and in vitro (54) to fatty acid and glycerol. The most probable source of the 1 -monoolein present in intestinal content is from the isomerization of the 2 -isomer. In addition to 1-monoolein, biliary lecithin is an additional source of fatty acid; it is cleaved to lysolecithin and fatty acid by a pancreatic lecithinase $(40,41)$.

There is only indirect evidence for the second possibility. For a balanced equation, on a molar basis, fatty acid must be absorbed at a rate twice that of monoglyceride absorption. However, recent perfusion experiments in man have suggested that monoglyceride may be absorbed as rapidly or more rapidly than fatty acid from a micellar solution (24). Similar rates of absorption of fatty acid and monoglyceride would lead to a relative molar excess of fatty acid. It was noted above that specimens were obtained that appeared to have undergone complete digestion and extensive absorption; such samples contained fatty acid and cholesterol, but no monoglyceride. The much lower concentration of diglyceride in the micellar phase ought to mean that diglyceride was absorbed less rapidly than fatty acid, an effect which would offset the consequences of identical rates of absorption of fatty acid and monoglyceride.

Freshly extracted human intestinal content, when examined by thin-layer chromatography, may contain monoglyceride entirely in the 2 -isomer form (29). Even if it is assumed that all of the periodate oxidizable material in the lipid extract is monoglyceride, a quantitative interpreta- 
TABLE I

Fatty acid, monoglyceride, diglyceride, and triglyceride

\begin{tabular}{|c|c|c|c|c|c|c|c|c|c|c|}
\hline \multirow{2}{*}{$\begin{array}{c}\text { Sample } \\
\text { no. }\end{array}$} & \multirow[b]{2}{*}{ Date } & \multirow[b]{2}{*}{ Subject } & \multirow{2}{*}{$\begin{array}{c}\text { Collection } \\
\text { interval }\end{array}$} & \multirow{2}{*}{$\begin{array}{l}\text { Collection } \\
\text { site }\end{array}$} & \multirow[b]{2}{*}{ Type } & \multirow{2}{*}{$\begin{array}{l}\text { Total } \\
\text { lipid }\end{array}$} & \multicolumn{4}{|c|}{ Composition by weight* } \\
\hline & & & & & & & FA & MG & DG & TG \\
\hline & & & hours & $\mathrm{cm}$ & & $m g / m l$ & \multicolumn{4}{|c|}{$m g / m l$} \\
\hline 6 & $3 / 16 / 61$ & A.H. & $1-1 \frac{1}{2}$ & 180 & Micellar & 3.31 & 3.23 & 0.85 & 0.03 & 0.0 \\
\hline 7 & $3 / 16 / 61$ & A.H. & $1-1 \frac{1}{2}$ & 180 & Total & 3.98 & 3.97 & 0.34 & 0.52 & 0.0 \\
\hline 10 & $3 / 16 / 61$ & A.H. & $1 \frac{1}{2}-2$ & 180 & Oil & $(650)$ & 306.0 & 272.0 & 78.0 & 113.0 \\
\hline 8 & $3 / 16 / 61$ & A.H. & $\frac{1}{2}-1$ & 180 & Total & 3.60 & 2.52 & 0.0 & 0.65 & 0.52 \\
\hline 11 & $5 / 19 / 61$ & S.W. & $0-\frac{1}{2}$ & 100 & Micellar & 2.83 & 1.67 & 0.23 & 0.14 & 0.16 \\
\hline $12 \nmid \dagger$ & $5 / 19 / 61$ & S.W. & $0-\frac{1}{2}$ & 100 & Total & 6.44 & 2.87 & 1.13 & 1.17 & 0.55 \\
\hline 135 & $5 / 19 / 61$ & S.W. & $0-\frac{1}{2}$ & 100 & Total & 7.43 & 3.45 & 1.40 & 0.94 & 0.79 \\
\hline 14 & $5 / 19 / 61$ & S.W. & $\frac{1}{2}-1$ & 100 & Micellar & 2.53 & 1.70 & 0.55 & 0.20 & 0.25 \\
\hline 15$\}$ & $5 / 19 / 61$ & S.W. & $\frac{2}{\frac{1}{2}-1}$ & 100 & Total & 4.00 & 2.57 & 0.70 & 0.15 & 0.27 \\
\hline 16$\}$ & $5 / 19 / 61$ & S.W. & $\frac{1}{2}-1$ & 100 & Total & 4.13 & 2.16 & 0.42 & 0.30 & 0.03 \\
\hline 17 & $5 / 19 / 61$ & S.W. & $2-2 \frac{1}{2}$ & 100 & Total & 3.18 & 1.62 & 0.66 & 0.44 & 0.39 \\
\hline 18$\}$ & $5 / 19 / 61$ & S.W. & $2-2 \frac{1}{2}$ & 100 & Total & 2.55 & 1.23 & 0.65 & 0.41 & 0.27 \\
\hline 19 & $5 / 19 / 61$ & S.W. & $\frac{1}{2}-1$ & 100 & Micellar & 7.00 & 4.54 & 1.95 & 0.63 & 0.25 \\
\hline 20$\}$ & $5 / 19 / 61$ & S.W. & $\frac{1}{2}-1$ & 100 & Total & 16.95 & 7.59 & 3.12 & 2.92 & 4.60 \\
\hline 21$\}$ & $5 / 19 / 61$ & S.W. & $\frac{1}{2}-1$ & 100 & Total & 16.23 & 7.51 & 2.05 & 2.02 & 3.29 \\
\hline $22 \ddagger$ & $5 / 19 / 61$ & S.W. & $1-2 \frac{1}{2}$ & 100 & Micellar & 2.73 & 2.60 & 0.16 & 0.10 & 0.15 \\
\hline $23^{+}$ & $5 / 19 / 61$ & S.W. & $1-2 \frac{1}{2}$ & 100 & Oil & $(890)$ & 251.0 & 273.0 & 206.0 & 107.0 \\
\hline 24$\}$ & $5 / 14 / 61$ & C.C. & $\frac{1}{2}-1$ & 75 & Micellar & 7.03 & 6.26 & 0.61 & 0.0 & 0.0 \\
\hline 25$\}$ & $5 / 14 / 61$ & C.C. & $\frac{1}{2}-1$ & 75 & Micellar & 6.32 & 5.92 & 0.36 & 0.0 & 0.08 \\
\hline 26 & $5 / 14 / 61$ & C.C. & $\frac{1}{2}-1$ & 75 & Total & 35.60 & 21.19 & 5.70 & 3.76 & 4.95 \\
\hline $28 \S$ & $5 / 17 / 61$ & L.L. & $\frac{1}{2}-1$ & 75 & Micellar & 2.33 & 2.10 & 0.43 & 0.18 & 0.09 \\
\hline $29^{\circ}$ & $5 / 17 / 61$ & L.L. & $\frac{1}{2}-1$ & 75 & Total & 16.76 & 10.59 & 3.16 & 0.91 & 2.41 \\
\hline 33$\}$ & $3 / 15 / 61$ & A.H. & $\frac{1}{2}-1$ & 90 & Total & 6.46 & 5.26 & 0.73 & 1.27 & 1.10 \\
\hline 34$\}$ & $3 / 15 / 61$ & A.H. & $\frac{1}{2}-1$ & 90 & Total & 6.43 & 4.14 & 0.38 & 1.76 & 1.27 \\
\hline 1) & $3 / 1 / 61$ & O.R. & Not recorded & Not recorded & Micellar & 1.83 & 1.14 & 0.11 & 0.09 & 0.06 \\
\hline 2$\}$ & $3 / 1 / 61$ & O.R. & Not recorded & Not recorded & Micellar & 1.78 & 1.14 & 0.20 & 0.11 & 0.07 \\
\hline
\end{tabular}

* FA = fatty acid; MG, DG, and TG = mono-, di-, and triglycerides.

$\dagger$ Braces indicate duplicate samples from one collection.

¥ Samples 22 and 23 were the micellar and oil phases, respectively, of one collection. The subject was fed the test meal in the morning (samples 14 and 18) and in the afternoon (samples 19 and 23).

$\S$ Samples 28 and 29 were the micellar and total phases, respectively, of one collection.

tion of the size of the fraction of monoglyceride present as the 1 - and 2 -isomer is impossible, as nothing is known of the relative absorption rate of the two isomers or the extent to which the 1 -isomer is hydrolyzed in the presence of an oil phase containing diglyceride and triglyceride.

The data thus show the existence of a micellar phase, the lipids of which-fatty acids and monoglycerides-correspond to the chemical form in which lipid has been thought for some time to be absorbed (55). Recent electron microscopic studies $(56,57)$ of fat absorption have noted the virtual absence of particulate lipid passing into the microvilli, despite evidence from the appearance of lipid droplets in the lumen and the cell that fat absorption was proceeding actively. Such experimental findings have been interpreted as indicating that lipid is absorbed in an aggregate the size of which is beyond the resolution of the electron microscope, an interpretation in complete agreement with our view that lipid is nor- mally absorbed from a micellar solution. Pinocytosis of fat droplets at the membrane of the microvilli of the intestinal mucosal cell has been observed (58), but its quantitative significance is unclear.

Although it is clear that ingested triglyceride is surely emulsified to some extent before lipolysis, our view is that emulsification is a preliminary step to micellar solubilization and that emulsion droplets are not absorbed as such. It has been shown that the human intestine readily absorbs fatty acid and monoglyceride when perfused with a micellar solution of these lipids (24). Micellar fatty acid and monoglyceride are absorbed and acylated to triglyceride by everted hamster gut sacs or intestinal slices (59).

The data speak for the absorption of lipid chiefly in the form of fatty acid and 2-monoglyceride from a micellar solution. Smaller amounts of 1-monoglyceride and still smaller amounts of diglyceride and triglyceride may also be absorbed. 
TABLE I

concentrations of intestinal content samples

\begin{tabular}{|c|c|c|c|c|c|c|c|c|c|}
\hline \multirow[b]{2}{*}{ Sum } & \multirow[b]{2}{*}{ Recovery } & \multicolumn{4}{|c|}{ Composition by weight } & \multicolumn{4}{|c|}{ Molar composition } \\
\hline & & FA & MG & DG & TG & FA & MG & DG & TG \\
\hline$m g / m l$ & $\%$ & $\%$ & $\%$ & $\%$ & $\%$ & \multicolumn{4}{|c|}{$\mu$ moles $/ m l$} \\
\hline 4.01 & 121 & 78.5 & 20.6 & 0.7 & 0.0 & 14.40 & 2.38 & 0.05 & 0.0 \\
\hline 4.83 & 121 & 82.2 & 7.1 & 10.7 & 0.0 & 14.05 & 0.96 & 0.84 & 0.0 \\
\hline 769.0 & 118 & 39.8 & 35.4 & 10.1 & 14.7 & $1,080.0$ & 760.0 & 125.0 & 128.0 \\
\hline 3.69 & 102 & 68.2 & 0.0 & 17.6 & 14.1 & 8.90 & 0.0 & 1.05 & 0.59 \\
\hline 2.20 & 78 & 75.9 & 10.5 & 6.4 & 7.3 & 5.90 & 0.65 & 0.23 & 0.18 \\
\hline 5.72 & 89 & 50.2 & 19.7 & 20.4 & 9.6 & 10.15 & 3.17 & 1.88 & 0.62 \\
\hline 6.58 & 89 & 52.4 & 20.3 & 14.3 & 12.0 & 12.42 & 3.93 & 1.51 & 0.89 \\
\hline 2.70 & 107 & 59.0 & 22.5 & 8.2 & 10.2 & 6.02 & 1.54 & 0.32 & 0.28 \\
\hline 3.69 & 92 & 69.6 & 19.0 & 4.1 & 7.3 & 9.10 & 1.96 & 0.24 & 0.30 \\
\hline 2.91 & 71 & 74.2 & 14.4 & 10.3 & 1.0 & 7.65 & 1.18 & 0.48 & 0.03 \\
\hline 3.11 & 98 & 52.1 & 21.2 & 14.3 & 12.5 & 5.73 & 1.85 & 0.71 & 0.44 \\
\hline 2.56 & 100 & 48.0 & 25.4 & 16.0 & 10.6 & 4.35 & 1.82 & 0.66 & 0.30 \\
\hline 7.37 & 105 & 58.0 & 28.9 & 9.3 & 3.7 & 16.05 & 5.46 & 1.01 & 0.28 \\
\hline 18.23 & 108 & 41.6 & 17.1 & 16.0 & 25.2 & 26.80 & 8.80 & 4.70 & 5.20 \\
\hline 14.87 & 92 & 50.5 & 13.8 & 13.6 & 22.2 & 26.60 & 5.80 & 3.20 & 3.70 \\
\hline 3.01 & 110 & 86.5 & 5.3 & 3.3 & 5.0 & 9.20 & 0.45 & 0.16 & 0.17 \\
\hline 837.0 & 94 & 30.0 & 32.6 & 24.6 & 12.8 & 890.0 & 765.0 & 330.0 & 120.0 \\
\hline 6.87 & 98 & 91.2 & 8.8 & 0.0 & 0.0 & 22.20 & 1.71 & 0.0 & 0.0 \\
\hline 6.36 & 101 & 93.0 & 5.0 & 0.0 & 1.4 & 21.00 & 1.01 & 0.0 & 0.10 \\
\hline 35.60 & 126 & 59.5 & 16.0 & 10.5 & 13.9 & 75.00 & 16.00 & 6.00 & 5.60 \\
\hline 2.80 & 120 & 75.0 & 15.3 & 6.5 & 3.2 & 7.44 & 1.21 & 0.29 & 0.10 \\
\hline 17.07 & 102 & 62.0 & 18.5 & 5.3 & 14.1 & 37.50 & 8.85 & 1.47 & 2.72 \\
\hline 8.36 & 129 & 62.9 & 8.7 & 15.2 & 13.2 & 18.65 & 2.05 & 2.04 & 1.24 \\
\hline 7.55 & 119 & 54.8 & 5.0 & 23.3 & 16.9 & 14.60 & 1.06 & 2.84 & 1.44 \\
\hline 1.40 & 77 & 81.4 & 7.9 & 6.4 & 4.3 & 4.05 & 0.31 & 0.14 & 0.07 \\
\hline 1.52 & 85 & 75.2 & i3. 2 & 7.2 & 4.6 & 4.05 & 0.56 & 0.18 & 0.08 \\
\hline
\end{tabular}

The mechanism by which micellar lipid passes into the cell is unknown. Net bile salt absorption occurs in the distal small intestine (24), and the amount of bile salt excreted during a meal is too little to solubilize all of the monoglyceride and fatty acid derived from dietary triglyceride. Therefore, the bile salt micelle probably serves a transport function, dissolving the lipid and thus aiding its movement up to the cell.

\section{Summary}

After the feeding of a test meal containing corn oil, human small intestinal content was collected by intubation and heated for 10 minutes at $70^{\circ} \mathrm{C}$ to inactivate pancreatic lipase. The intestinal content was then centrifuged for 18 hours at $100,000 \times g$ at 37 to $40^{\circ} \mathrm{C}$ and thus separated into a transparent, aqueous, micellar phase and a supernatant oil phase. The fatty acid and glyceride content of each phase was determined by titration and silicic acid chromatography.

The lipids of the lower, micellar phase were chiefly fatty acid and monoglyceride with smaller amounts of diglyceride and triglyceride. The lipids of the micellar phase differed from those of the oil phase in containing significantly more fatty acid and significantly less diglyceride and triglyceride.

Thin-layer chromatography showed the diglyceride to be largely 1,2 isomer. Five specimens of intestinal content were analyzed for 1 - and 2-monoglyceride content by periodate titration; twothirds of the monoglyceride was present as the 2 -isomer, on an average.

The results are consistent with the hypotheses that intestinal lipid, during fat digestion, is selectively partitioned between a micellar and an oil phase and that absorption of dietary lipid takes place from a micellar solution containing chiefly fatty acid and 2-monoglyceride.

\section{Acknowledgments}

The technical assistance of Mrs. Mai-Britt Nilsvik, Mrs. Gunilla Björklund, Miss Bodil Åkesson, and Miss Ulla Hansson is gratefully acknowledged.

\section{References}

1. Hofmann, A. F., and B. Borgström. Physico-chemical state of lipids in intestinal content during their digestion and absorption. Fed. Proc. 1962, 21, 43. 
2. Hofmann, A. F., and B. Borgström. The distinctive detergent properties of conjugated bile salts and their relation to the role of bile saits in fat digestion. J. clin. Invest. 1963, 42, 942.

3. Pflüger, E. Fortgesetzte Untersuchungen über die Resorption der künstlich gefärbeten Fette. Pflügers Arch. ges. Physiol. 1901, 85, 1.

4. Verzár, F., and E. J. McDougall. Absorption from the Intestine. London, Longmans, Green, 1936.

5. Artom, C., and L. Reale. The formation of intermediate products in the pancreatic digestion of neutral fat. Boll. Soc. ital. Biol. sper. 1936, 10, 867.

6. Frazer, A. C., and H. G. Sammons. The formation of mono- and di-glycerides during the hydrolysis of triglyceride by pancreatic lipase. Biochem. J. 1945, 39, 122.

7. Frazer, A. C., J. H. Schulman, and H. C. Stewart. Emulsification of fat in the intestine of the rat and its relationship to absorption. J. Physiol. (Lond.) 1944, 103, 306.

8. Frazer, A. C. Fat absorption and its disorders. Brit. med. Bull. 1958, 14, 212.

9. Sjöstrand, F. S., and H. Zetterqvist in Bergström, S., and B. Borgström. The intestinal absorption of fats in Progr. Chemistry Fats and Other Lipids, R. T. Holman, W. O. Lundberg, and T. Malkin, Eds. London, Pergamon Press, 1955, vol. 3, p. 388.

10. Palay, S. L., and L. J. Karlin, An electron microscopic study of the intestinal villus. I. The fasting animal. J. biophys. biochem. Cytol. 1959, 5, 363.

11. Moore, B., and D. P. Rockwood. On the mode of absorption of fats. J. Physiol. (Lond.) 1897, 21, 58.

12. Ekwall, P., K. Fontell, and A. Sten. Micelle formation in bile salt solutions in Gas/Liquid and Liquid/ Liquid Interface, Proc. 2nd Int. Congr. Surface Activity, J. H. Schulman, Ed. London, Butterworth, 1957, p. 357.

13. Norman, A. The beginning solubilization of 20methylcholanthrene in aqueous solutions of conjugated and unconjugated bile acid salts. Bile acids and steroids 79. Acta chem. scand. 1960, 14, 1295.

14. Hofmann, A. F. The role of bile salts in fat absorption: the solvent properties of dilute, micellar solutions of conjugated bile salts. Biochem. J. 1963, 89, 57.

15. Hartley, G. S. Aqueous solutions of paraffin chain salts in Actualités Scientifiques et Industrielles. Paris, Hermann, 1936, p. 4.

16. Pankhurst, K. G. A. Detergent solutions in Lect. Royal Inst. of Chemistry. London, 1953, p. 1.

17. Garrett, H. E. Aggregation in detergent solutions in Surface Activity and Detergency, K. Durham, Ed. London, Macmillan, 1961, p. 29.

18. McBain, M. E. L., and E. Hutchinson. Solubilization and Related Phenomena. New York, Academic Press, 1955, p. 1.
19. Hofmann, A. F. The behaviour and solubility of monoglycerides in dilute, micellar bile salt solution. Biochim. biophys. Acta (Amst.) 1963, 70, 306.

20. Blankenhorn, D. H., J. Hirsch, and E. H. Ahrens, Jr. Transintestinal intubation: technic for measurement of gut length and physiologic sampling at known loci. Proc. Soc. exp. Biol. (N. Y.) 1955, 88, 356.

21. Dahlquist, A., and B. Borgström. Digestion and absorption of disaccharides in man. Biochem. J. 1961, 81, 411.

22. Mangold, H. K. Aliphatische Lipide in Dünnschichtschromatographie, ein Laboratoriums Handbuch, E. Stahl, Ed. Berlin, Springer Verlag, 1962, p. 141.

23. Blankenhorn, D. H., and E. H. Ahrens, Jr. Extraction, isolation and identification of hydrolytic products of triglyceride digestion in man. J. biol. Chem. 1955, 212, 69.

24. Borgström, B., G. Lundh, and A. F. Hofmann. The site of absorption of conjugated bile salts in man. Gastroenterology. 1963, 45, 229.

25. Rapport, M.M., and N. Alonzo. Photometric determination of fatty acid ester groups in phospholipides. J. biol. Chem. 1955, 217, 193.

26. Desnuelle, P., and M. J. Constantin. Formation de glycérides partiels pendant la lipolyse des triglycérides dans l'intestin. Biochim. biophys. Acta (Amst.) 1952, 9, 531.

27. Hartman, L. The $\beta$-monoester content of commercial monoglycerides after prolonged storage. J. Sci. Food Agric. 1960, 11, 191.

28. Hofmann, A. F. Thin-layer adsorption chromatography of lipids in Proc. 7th Int. Cong. Biochemical Problems of Lipids, A. C. Frazer, Ed. Amsterdam, Elsevier, 1963, p. 1.

29. Hofmann, A. F. Separation of 1- and 2-monoglycerides by thin-layer adsorption chromatography on hydroxyl-apatite. J. Lipid Res. 1962, 3, 391.

30. Hofmann, A. F. Thin-layer adsorption chromatography of free and conjugated bile acids on silicic acid. J. Lipid Res. 1962, 3, 127.

31. Borgström, B. Studies on pancreatic lipase in Biochemical Problems of Lipids, Proc. 2nd Int. Conf., Univ. of Ghent, 1955, G. Popják and E. Le Breton, Eds. London, Butterworth, 1956, p. 179.

32. Terroine, E. F. Zur Kenntnis der Fettspaltung durch Pankreassaft II. Biochem. Z. 1910, 23, 404.

33. Borgström, B. Studies on intestinal cholesterol absorption in the human. J. clin. Invest. 1960, 39, 809.

34. Borgström, B., A. Dahlqvist, G. Lundh, and J. Sjövall. Studies of intestinal digestion and $a b-$ sorption in the human. J. clin. Invest. 1957, 36, 1521. 
35. Wallis, W. A., and H. V. Roberts. Statistics, A New Approach. Glencoe, Ill., Free Press, 1956, p. 418.

36. Mattson, F. H., and L. W. Beck. The specificity of pancreatic lipase for the primary hydroxyl groups of glycerides. J. biol. Chem. 1956, 219, 735.

37. Privett, O. S., and M. L. Blank. A new method for the analysis of component mono-, di-, and triglycerides. J. Lipid Res. 1961, 2, 37.

38. Dowse, C. M., J. A. Saunders, and B. Schofield. The composition of lipid from jejunal contents of the dog after a fatty meal. J. Physiol. (Lond.) 1956, 134, 515.

39. Osipow, L. I. Surface Chemistry. New York, Reinhold, 1962, p. 129.

40. Borgström, B. Studies of the phospholipids of human bile and small intestinal content. Acta chem. scand. 1957, 11, 749.

41. Vogel, W. C., and L. Zieve. A lecithinase A in duodenal contents of man. J. clin. Invest. 1960, 39, 1295.

42. Hofmann, A. F. Unpublished observations.

43. Shinoda, K., and E. Hutchinson. Pseudo-phase separation model for thermodynamic calculations on micellar solutions. J. phys. Chem. 1962, 66, 577.

44. Ahrens, E. H., Jr., and B. Borgström. Exchange of free fatty acids and glyceride fatty acids during fat digestion in the human intestine. J. biol. Chem. 1956, 219, 665.

45. Borgström, B., N. Tryding, and G. Westöö. On the extent of hydrolysis of triglyceride ester bonds in the lumen of human small intestine during digestion. Acta physiol. scand. 1957, 40, 241.

46. Borgström, B. The formation of new glycerideester bonds during digestion of glycerides in the lumen of the small intestine of the rat. Arch. Biochem. 1954, 49, 268.

47. Knoebel, L. K., and J. M. Ryan. Digestion and mucosal absorption of fat in normal and bile-deficient dogs. Amer. J. Physiol. 1963, 204, 509.

48. Gidez, L. I., and M. L. Karnovsky. The metabolism of glyceride-glycerol. J. biol. Chem. 1956, 223, 293.
49. Favarger, P., R. A. Collet, and E. Cherbuliez. Etude de la résorption intestinale des graisses à l'aide de deutéroglycérol et d'acides gras marqués. Helv. chim. Acta 1951, 34, 1641.

50. Bernhard, K., H. Wagner, and G. Ritzel. Versuche zur quantitativen Erfassung der bei der Resorption von Neutralfett eintretenden Spaltung. Helv. chim. Acta 1952, 35, 1404.

51. Borgström, B. On the action of pancreatic lipase on triglyceride in vivo and in vitro. Acta physiol. scand. 1952, 25, 328.

52. Constantin, M. J., L. Pasero, and P. Desnuelle. Quelques remarques complémentaires sur l'hydrolyse des triglycerides par la lipase pancréatique. Biochim. biophys. Acta (Amst.) 1960, 43, 103.

53. Ahrens, E. H., Jr., and B. Borgström. Fatty acid exchanges during fat digestion in the human intestine in Biochemical Problems of Lipids, Proc. 2nd Int. Conf., Univ. of Ghent, 1955, G. Popják and E. Le Breton, Eds. London, Butterworth, 1956, p. 315.

54. Hofmann, A. F., and B. Borgström. The hydrolysis of long-chain monoglycerides in micellar solution by pancreatic lipase. Biochim. biophys. Acta (Amst.) 1963, 70, 317.

55. Reiser, R. Recent studies of fat digestion and absorption. Clin. Chem. 1955, 1, 93.

56. Shiner, M., D. Lacy, and R. H. Hudson. Electron microscope study of fat absorption in normal subjects and in patients with idiopathic steatorrhoea in Intestinal Biopsy (Ciba Foundation Study Group No. 14), G. E. W. Wolstenholme and M. P. Cameron, Eds. Boston, Little, Brown, 1962, p. 24.

57. Sjöstrand, F. S. Personal communication.

58. Palay, S. L., and L. J. Karlin. An electron microscopic study of the intestinal villus II. The pathway of fat absorption. J. biophys. biochem. Cytol. 1959, 5, 373.

59. Johnston, J. M., and B. Borgström. Intestinal uptake of micellar solutions of fatty acids and monoglycerides (abstract). Acta chem. scand. 1963, 17, 905. 